\title{
Carcinoma de células escamosas diagnosticados em bovinos no sertão da Paraíba
}

Millena de Oliveira Firmino", Artéfio Martins de Oliveira, Rodrigo Cruz Alves, Robério Gomes Olinda, Júlio Edson da Silva Lucena, Daniel Medeiros de Assis, Eldinê Gomes Miranda Neto, Antônio Flávio Medeiros Dantas

Programa de Pós-Graduação em Medicina Veterinária, Centro de Saúde e Tecnologia Rural, Universidade Federal de Campina Grande (UFCG), Patos, PB, Brasil

*Autor correspondente

e-mail: millena_deoliveira@yahoo.com.br

\section{Resumo}

Carcinoma de células escamosas (CCE) é o neoplasma mais frequente em bovinos, responsável por grandes perdas econômicas devido à redução na vida reprodutiva ou à condenação de carcaças em abatedouros. Vários fatores podem estar relacionados ao aparecimento dessa neoplasia, tais quais raça, grau de pigmentação da pele e fatores ambientais, como incidência de raios ultravioletas. Os olhos, vulva e base do chifre são os locais mais afetados nesta espécie. Portanto, objetiva-se com esse trabalho descrever os achados epidemiológicos, clínicos e anatomopatológicos do CCE diagnosticados em bovinos no sertão da Paraíba. Foi realizado um estudo retrospectivo do período entre janeiro de 2006 a dezembro de 2016 no Laboratório de Patologia Animal, Universidade Federal de Campina Grande, Patos-PB, no qual foram revisadas todas as fichas de biopsias e necropsias de bovinos que apresentavam diagnóstico conclusivo de CCE e analisados os dados referentes a sexo, raça, idade, localização das lesões e sinais clínicos. Durante o período estudado, foram diagnosticados 48 casos de CCE em bovinos no sertão da Paraíba, sendo 37 oriundos de biopsias e 11 necropsias. Destes, 45 eram fêmeas e 3 machos. 16 animais eram da raça Holandesa, 26 eram sem raça definida, em sua maioria mestiços de Holandês, um girolanda e em 5 casos a raça não foi informada. Todos os animais afetados eram adultos com idade variando entre 3 a 18 anos. A região mais afetada foi a vulva (11/48), globo ocular (10/48) e seus anexos como terceira pálpebra (7/48) e pálpebra (4/48), pele da região de mandíbula (1/48), região frontal da cabeça (1/48), base do chifre $(2 / 48)$, dorso $(5 / 48)$ e lombar $(1 / 48)$. A glândula mamária foi afetada em dois casos (2/48). Em três casos o local da lesão não foi informado. Dos animais que foram necropsiados (11/48), em quatro casos foi observado metástase em linfonodos regionais (3/4), pleura parietal (2/4), diafragma (1/4) e saco pericárdico (2/4). Macroscopicamente as lesões eram caracterizadas por massas ou nódulos geralmente ulcerados associados à infecção secundária 
e miíases, por vezes associado a conteúdo serossanguinolento. Na superfície de corte apresenta-se branco-amarelada, irregular e de aspecto granular. Microscopicamente as lesões eram caracterizadas por proliferação da camada epidérmica, com formação de cordões e ninhos na derme superficial e presença de queratinização individual ou de pérolas córneas em meio à proliferação epitelial maligna. A literatura descreve que geralmente os CCE se desenvolvem em regiões despigmentadas e com quantidade pequena de pêlos, como na região periorbital e genital, assim como foi observado na maioria dos casos. Geralmente a exérese cirúrgica tem resultado satisfatório, já que esse neoplasma não costuma provocar metástases, porém de caráter infiltrativo, o que pode promover destruição óssea, necrose e infecção secundária nos tecidos adjacentes e, consequentemente, diminuição de peso e prejuízos econômicos, principalmente nos bovinos leiteiros. 